\title{
ANDRÉS RIVERA DESDE LA FENOMENOLOGÍA ALEGÓRICA. ANÁLISIS DE LA NOVELA LA REVOLUCIÓN ES UN SUEÑO ETERNO
}

\author{
Daniel Nemrava
}

\begin{abstract}
The article proposes an allegoric interpretation of the experimental novel La revolución es un sueño eterno (The Revolution is an Eternal Dream, 1987), a masterpiece by the Argentinian writer Andrés Rivera (1928). Our hypothesis is that rather than an attempt to fill in the empty spaces of the Argentinian official 19th century historiography, Rivera uses the memories of a history-based character Juan José Castelli to reflect upon the existential crisis of a modern man. In our opinion, the fragmentary and labyrinthine nature of the text, the splitting of the narrator and the chronotopic distortion thematize the process of creative writing itself and its crisis. We consider various concepts of allegoric phenomenology to be the most appropriate way to approach this problem.

Keywords: experimental novel; Argentina; The May Revolution; allegory; melancholy.

Resumen: Nuestro trabajo propone una lectura alegórica de la novela experimental La revolución es un sueño eterno (1987), obra maestra del escritor argentino Andrés Rivera (1928). Según nuestra hipótesis, tal vez más que rellenar un vacío en la historiografía oficial de la Argentina del siglo XIX el autor presenta, a través de las memorias del personaje histórico Juan José Castelli, una profunda reflexión de la crisis existencial del hombre moderno. Sostenemos que por el carácter fragmentario y laberíntico del texto, la escisión del narrador y la distorsión cronotópica se tematiza la propia escritura y su crisis. Para el análisis de esta problemática consideramos como más apropiada la aplicación de algunos conceptos de la fenomenología alegórica.
\end{abstract}

Palabras claves: novela experimental; Argentina; Revolución de Mayo; alegoría; melancolía.

\section{Introducción}

En el estudio de la alegoría, la crítica moderna centra su atención sobre todo en su plasmación en el nivel lingüístico, destacando uno de sus problemas fundamentales: la relación arbitraria entre el significante y el significado. A partir de El origen del drama barroco alemán (1928) de Walter Benjamin, se rehabilita el topos de la alegoría interpretada como una de las formas claves para el conocimiento del mundo, como un método epistemológico de validez universal. Craig Owens define los temas benjaminianos relacionados con la alegoría de la siguiente manera: «el progreso como eterno retorno de la catástrofe; la crítica como la intervención redentora en el pasado; el valor teórico de lo concreto, lo dispar, lo discontinuo» (Owens 1991: 40). Posteriormente, la alegoría llevaría a Benjamin a la interpretación de la modernidad y a encontrar paralelos entre el barroco y el expre- 
sionismo. En el trabajo arriba mencionado, Benjamin (1990: 155) atribuye a la alegoría las cualidades propias de la escritura al decir que la alegoría «no es una técnica gratuita de producción de imágenes, sino expresión, de igual manera que lo es el lenguaje, y hasta la escritura». En poder de lo alegórico los objetos adquieren otros significados:

...la cosa se transforma en algo distinto y él habla así de algo diferente, y la cosa se convierte para él en la clave de un dominio de saber escondido, y como emblema de ese saber él la venera. Esto es lo que hace de la alegoría una escritura. La alegoría es un esquema y, en cuanto tal, objeto del saber, sólo inalienable a éste en cuanto que es algo fijado: imagen fijada y signo que fija al mismo tiempo (Benjamin 1990: 177).

De este modo, Benjamin refleja el carácter alegórico de la letra subrayando su carácter subjetivo.

Petr Málek, en su estudio sobre la melancolía de la modernidad literaria centroeuropea, destaca el carácter de la alegoría benjaminiana como una forma de expresión melancólica de la vanidad de las cosas. Málek distingue dos niveles de funcionamiento para la alegoría. Por una parte, un nivel de significado en el que la alegoría es válida como un mero signo donde se manifiesta extraordinariamente el principio de lo arbitrario; por otra parte, tendríamos un nivel de meta-significado, donde la alegoría resulta ser una expresión del estado existencial de la tristeza, de la melancolía (Málek 2008: 58).

Benjamin imagina la alegoría como una escritura sagrada, lo que lo lleva a descubrir el carácter antitético o dialéctico de la alegoría entre la arbitrariedad del significado y la autoridad sagrada de la alegoría como escritura. La alegoría es entonces el ejemplo último de la re-denominación después de la caída en pecado, representando el mundo profano del «conocimiento», un mundo escéptico donde se perdió el vínculo sagrado entre las cosas y sus propios significados (o sus nombres).

Esta preocupación que analiza Benjamin resurge con gran intensidad con las primeras manifestaciones de las vanguardias, que empiezan a tematizar el problema de la crisis de la lengua (de la palabra), es decir, la crisis del conocimiento.

Según Málek, la escritura en la modernidad ya no es percibida como...

...signatura del proyecto divino que se anunciaba en el libro de la naturaleza para después ser comentado en libros humanos. Ya quedan sólo unos signos dispersos, desparramados, restos de un texto escrito que había sido destruido, ruinas de una arquitectura remota, una escritura fragmentada -a la vez sagrada e inaprehensible- y su sentido, es decir, un sinnúmero de significados que podemos descifrar/construir, un sentido que puede ser sólo arbitrario y así fragmentario (Málek 2008: 73) ${ }^{1}$.

La fragmentación o discontinuidad a la que alude Málek está relacionada con el hecho de que la alegoría es frecuentemente aprovechada en la literatura contemporánea como un instrumento para expresar la crisis y la derrota histórica. Idelber Avelar, en su lectura de textos de la narrativa hispanoamericana de la época postdictatorial de finales del siglo XX, apunta que en las obras alegóricas...

...todo el texto se subsume bajo la lógica propia a las tiranías retratadas. Al eliminarse toda coexistencia de modos de producción (y sus lógicas respectivas), el fundamento de esas tiranías o catástrofes se hace invisible a los personajes, narrador y lector, inimputable a la volun-

\footnotetext{
1 Según el texto original: «signaturou božího záměru, který se oznamoval v knize př́rody, aby v knihách lidských byl pak komentován. Jsou již jen rozptýlené, roztroušené znaky, zbytky napsaného textu, jenž byl zničen, ruiny zašlé architektury, rozpadlé písmo - zároveň posvátné a nesrozumitelné - a jeho smysl, totiž bezpočet významů, jež můžeme dešifrovat/konstruovat, tedy smysl, jenž může být pouze libovolný, a tedy fragmentární» (la traducción del checo es nuestra).
} 
tad o la acción de cualquier sujeto. La rígida circunscripción espacio-temporal común a estos textos se analiza dentro de este marco: despliegan, al fin y al cabo, la petrificación de la historia característica de la alegoría. Esta inmanentización radical se vincula [...] con la experiencia de la derrota, cuya réplica tropológica reside en el concepto de alegoría: derrota histórica, inmanentización de los fundamentos de la narrativa y alegorización de los mecanismos ficcionales de representación, serían teóricamente coextensivos, cooriginarios [...]. [E]l giro hacia la alegoría equivale a una transmutación epocal, paralela y coextensiva a la imposibilidad de representarse el fundamento último: derrota constitutiva de la productividad de lo literario, instalación, en fin, de su objeto de representación en cuanto objeto perdido (Avelar 2000: 27).

Por lo tanto, nosotros apoyamos la tesis de que la alegoría es probablemente el mejor instrumento retórico capaz de crear relaciones entre una situación socio-política y el lenguaje, posteriormente codificado en historias parabólicas o elusivas, el instrumento por excelencia para la ficcionalización del discurso no literario, para la representación de la historia -de acuerdo con Benjamin- como ruina "petrificada», la expresión retórica de la desesperanza. Las obras alegóricas son unos microcosmos textuales que alegóricamente representan una totalidad en el momento de la suspensión de la historia, del progreso, un momento de la eternalización de las experiencias.

\section{El revolucionario melancólico}

La revolución es un sueño eterno (1987) de Andrés Rivera ${ }^{2}$ es una ficción compleja escrita en forma de memorias, notas o reflexiones del personaje histórico Juan José Castelli (1764-1812), un jacobino argentino, orador de la Revolución de Mayo de 1810, quien se nos presenta en el momento trágico de su agonía, debida a un cáncer de lengua, cuando ya está desplazado del poder, empobrecido y juzgado en el proceso político. El tiempo del relato transcurre entre diciembre de 1811 y octubre de 1812, es decir, desde el inicio del proceso hasta la muerte del protagonista. Por lo tanto, las memorias de Castelli giran sobre todo en torno a momentos del juicio y al episodio histórico que lo precede, el de la campaña de Castelli en Alto Perú con el Ejército del Norte, que fue derrotado por el general José Manuel de Goyenche en la batalla de Huaqui el 20 de julio de 1811. Precisamente este hecho fue un pretexto para los adversarios políticos de Castelli, a quien se lo acusó de ser responsable de la derrota. Tras su muerte, la causa jamás fue sentenciada y el juicio quedó abierto.

La novela tematiza la propia escritura. Si bien su estilo remite a la oralidad, dadas las frecuentes repeticiones de adjetivos o de frases enteras, interrupciones en la enunciación y distorsiones cronotópicas, se trata ante todo de un texto que ficcionaliza el proceso de escritura en el que el narrador corrige lo escrito, lo comenta y vuelve a reescribirlo. Además, las memorias de Castelli son un texto genéricamente híbrido que, junto con el relato de los episodios de su vida pública y privada, abarca también cartas, actas del juicio y un memorando. El libro consta de dos partes, que en el nivel diegético corresponden a dos cuadernos de tapas rojas escritos por Castelli, y el apéndice/paratexto con biografías de algunos personajes históricos secundarios. Lo que relaciona la historia de Castelli con los tiempos modernos son las citas de Perón y Lenin que introducen la ficción y una nota,

\footnotetext{
2 Andrés Rivera nació en Buenos Aires en 1928. Trabajó como obrero textil y periodista. Desde 1953 hasta 1957 fue redactor de la revista Plática. En 1985 obtuvo el Segundo Premio Municipal de Novela con En esta dulce tierra (1984). En 1992 recibió el Premio Nacional de Literatura. De entre las otras novelas del autor destacan La Sierva, distinguida como el mejor libro publicado en 1992 por la Fundación El Libro, Nada que perder (1982) o El Farmer (1996). También ha publicado los libros de cuentos Mitteleuropa y Cría de asesinos.
} 
en el apéndice, que en el nivel extradiegético se presenta como nota de la editorial, aludiendo a la revolución bolchevique. Así que en este paratexto el autor implícito remite directamente a la actualidad, resemantiza el concepto de la revolución desde la perspectiva actual, amplia el significado por la experiencia ideológica, por las consecuencias y los fracasos en el siglo XX. También las tapas rojas de los cuadernos de Castelli podrían remitir indirectamente a la misma revolución rusa.

Nos hemos preguntado si puede haber algún vínculo, en esta novela, entre la imagen alegórica del discurso del sujeto y su situación espacio-temporal; entre la escritura laberíntica de un personaje histórico de principios del siglo XIX y la melancolía del hombre contemporáneo. Nos hemos planteado hasta qué punto puede atravesar y determinar la melancolía el discurso identitario argentino que propone Andrés Rivera en su obra.

Edgardo H. Berg apunta que el topos recurrente en la obra de Rivera es la visión de la historia como un gran teatrum mundi que funciona como modelo arquitectónico clave en la estructuración de sus textos. El planteamiento teatral lo podemos ver en la novela, por ejemplo, en el desdoblamiento del narrador. Según Berg, los personajes, si quieren reconocerse en la historia, tienen que distanciarse y mutar en actores, crear entonces su alter ego y salir del escenario para poder contar su tragicomedia. Una vez realizada esa transmutación, es decir, cuando los actores desaparecen «del régimen de la Historia o la padecen como anagnórisis o rememoración, pueden entrever a contraluz el funcionamiento oculto de la máquina polifacética que desplaza los linajes paternos y permuta la cadena onomástica de la historia» (Berg 2002: 118). Las observaciones de Berg las podemos comprobar en el siguiente fragmento de la novela de Rivera:

\begin{abstract}
¿Qué soy? ¿Un actor que levanta sus ojos de un cuaderno de tapas rojas, y mira la transparente penumbra de una habitación sin ventanas, de techo alto, y que sugiere, desde ese escenario, al público que lo contempla, que el invierno llegó a la ciudad? (A la izquierda del escenario, un catre de soldado. A los pies del catre de soldado -para que yo no olvide, sea yo quien sea-, una manta color humo, limpia, doblada con prolijidad. En la cabecera del catre de soldado, enrollada, una capa azul, que huele a bosta y sangre. Entre la manta y la capa, un tablero de ajedrez: las treinta y dos piezas del juego son de peltre. El rey blanco y el rey negro parecen muy altos y muy encorvados, como si hubieran cargado un mundo sobre sus espaldas. Tienen cara, supongo, porque están encapuchados.)
\end{abstract}

¿Soy un actor que escribe que se ríe de él y de las vidas que vivió: que se ríe de la historia [...] y de los hombres que lo cruzan, de los papeles que encarnan y de los que renuncian a encarnar? ¿De las marionetas que proliferan, tenaces en el escenario de la historia, y que mastican ceniza?

[...] ¿Soy el público que contempla a un actor mudo, y que devuelve, con las simetrías implacables de un espejo, sus representaciones...? (Rivera 2000: 25-26).

El fragmento claramente ilustra el proceso del desdoblamiento, de la transmutación, el abandono del escenario de la Historia que permite al protagonista contemplar y contar su «historia» tragicómica. El protagonista es a la vez actor y «público que contempla», «actor que escribe»y «él» mismo. También, de acuerdo con la teoría de Málek, en el nivel de meta-significado, el protagonista, mudo y frustrado por el fracaso, contempla melancólicamente el gran teatro del mundo, concretamente el de la revolución independista argentina que, sin embargo, se convierte en una imagen estática (petrificada) de una escena que no cambia a lo largo de la novela. La Historia es representada así como ruina petrificada. 
Andrés Rivera desde la fenomenología alegórica...

Sabrina Riva (2007) observa que «el diario de Castelli plantea una escisión del narrador, porque el sujeto se ve a sí mismo, se ve como otro motivo de escritura, de ahí que se contemple como «otro». Así, en muchos pasajes el sujeto habla de él en tercera persona del singular: «Y en el escenario, cuya luz se extingue, el actor escribe: la revolución es un sueño eterno. Castelli escribe: es hora de comer mi ración de zapallo pisado» (Rivera 2000: 49). El sujeto/narrador se contempla a la vez o como actor o como espectador.

Podemos ver que en la novela el mismo narrador alegoriza su propia narración. En el cuadro alegórico creado por el protagonista surge ante nosotros, de repente, la imagen de un revolucionario melancólico en su agonía con el trasfondo caótico de los sucesos históricos. La teatralidad del texto es notable desde las primeras líneas del libro, y esa misma característica determina toda la narración, estructurada desde este punto de vista no tanto como un monólogo, sino, ya dentro del cuadro alegórico del teatro, como un diálogo entre el actor y su público. Gracias al distanciamiento del narrador por medio del proceso de alegorización, la historia en la novela «aparece bajo la metáfora teatral del escenario del mundo» (Berg 2002: 118).

La presentación de la diégesis como un teatro en el que el mismo narrador observa y comenta su propia función, su drama histórico en el que hace el papel de protagonista, funciona como metáfora para expresar la fragmentación de la identidad del sujeto que intenta eternizar o salvar su existencia en la escritura de los cuadernos de tapas rojas:

¿Quién escribe las preguntas que escribe esta mano? ¿El orador de la Revolución? ¿El representante de la Primera Junta en el ejército del Alto Perú? ¿El lengua cortada? ¿Quién de ellos dicta estos signos? ¿Acaso alguien que no es ninguno de ellos? (Rivera 2000: 99).

Y precisamente esa «fragmentación» se convierte en uno de los conceptos centrales dentro de la fenomenología alegórica que es necesario ver, sobre todo, en relación con la tematización de la escritura en la obra de Rivera.

El actor/Castelli, es decir, el protagonista desdoblado, permite crear un texto autorreflexivo y tematizar la dialéctica entre ilusión y realidad o realidad y verdad; tematizar a la vez la búsqueda de la identidad que nuestro héroe no encuentra.

\section{Las palabras y las cosas}

En La revolución es un sueño eterno se manifiesta la crisis epocal y existencial por medio del acto de escribir, desde la mente de Castelli que se pierde en su propio «monólogo» laberíntico. El texto resulta fragmentado, repetitivo, oscilando entre diégesis (el mundo narrado) y exégesis (metadiscurso). Es un laberinto de signos, cifras, es decir, el modelo metafórico por excelencia de la escritura alegórica. Por ejemplo, en la nota al final del libro leemos: «Algunas páginas son indescifrables: han sido escritas en código» (Rivera 2000: 170).

Resulta que entre la realidad y el sentido se abre un abismo:

No sé qué se hizo de mis palabras. Y yo, que maté, tengo miedo [...] Y esa palabra -miedono es nada, no habla, no es lágrima, no identifica, siquiera, ese líquido negro, vicioso, que le sube por el cuerpo, dentro del cuerpo, en esa ciudad que compra palabras y que las paga [...]

La palabra miedo no dice nada de lo que yo veo. No es miedo la palabra (Rivera 2000: 46-47).

Este fragmento lo podemos leer en sintonía con la teoría de Benjamin para quien la alegoría como figura retórica de la arbitrariedad representa la fragmentación de la totalidad 
divina, la rajadura o brecha abierta entre el significante y el significado, entre la expresión y la cosa, la discrepancia entre el mundo objetivo y su significación.

Podemos ver que la dialéctica de la alegoría planteada por Benjamin es perfectamente aplicable al discurso de Castelli: «Y no confundir lo real con la verdad» (Rivera 2000: 130). Estas palabras del protagonista pueden claramente ilustrar el proceso de la alegorización a través del cual podemos llegar a uno de los puntos determinantes que constituyen la estrategia narrativa de Rivera. De acuerdo con la lectura alegórica, la incompatibilidad de los conceptos de «lo real» y de la «verdad» corresponde a la incompatibilidad entre la formulación y la aplicación de la ley, aquí dentro del contexto de la Revolución de 1810. La verdad puede remitir a la verdad divina de la «Sagrada Escritura», que en la novela aparece en el siguiente contexto:

los pusilánimes anunciaron que me llevarían a juicio, engendro perverso de una revolución por cuyo mandato escribí a indios y esclavos somos iguales somos hermanos, y que testimoniarían contra los que concilian con el enemigo, y abjuran, despiertos o dormidos, desde que se consumió la hora efímera y tempestuosa y frágil de la revolución, de los horrores de la revolución, como si la revolución los hubiese defraudado, como si en alguna Sagrada Escritura se les hubiese asegurado que la revolución es un tratado de urbanidad, como si los que abjuran ignorasen que las buenas maneras no coexisten con la revolución bajo un mismo cielo, si hay un mismo cielo para las buenas maneras y la revolución (Rivera 2000: 126-127; cursiva en el original).

Esta Sagrada Escritura va precedida, sin embargo, del adjetivo indefinido «alguna», que tenemos que leer como una metáfora y que, por una parte, esconde una ironía, una risita dirigida a la Iglesia por parte del jacobino Castelli. Por otra parte, el mismo adjetivo remite a algo más grave e inquietante: el indefinido «alguna» puede también traducirse en el sentido de «una de varias». Es decir, el protagonista ya no percibe la escritura sagrada como única en su totalidad. La totalidad se perdió, ni siquiera se sabe si la podemos encontrar «bajo el mismo cielo», es fragmentada, revelando la arbitrariedad entre el significante y el significado, la discontinuidad de la naturaleza y la historia. Y dentro de la concepción benjaminiana, la misma rompe el contexto natural de las cosas. Esta pérdida es para Benjamin la fuente de la melancolía que se produce en el sujeto consciente de la ruptura, del abismo entre las palabras y las cosas, el hecho que le produce la incertidumbre existencial al hombre moderno, igual que a Castelli. Además, la palabra «alguna» podría significar algo así como olvidada, perdida, lejana, reveladora del abismo que se abre entre la palabra/verdad y la cosa/realidad en el nivel de la significación.

Con el texto de la novela entra en diálogo un libro fundamental: el Quijote, con el que identificamos a Castelli. Las batallas de Castelli resultan batallas quijotescas, siempre perdidas en tanto que ilusorias. Michel Foucault en Las palabras y las cosas (1966) afirma que el Quijote representa la ruptura del viejo compromiso entre las palabras y las cosas:

...las cosas permanecen obstinadamente en su identidad irónica: no son más que lo que son; las palabras vagan a la aventura, sin contenido, sin semejanza que las llene; ya no marcan las cosas; duermen entre las hojas de los libros en medio del polvo. La magia, que permitía el desciframiento del mundo al descubrir las semejanzas secretas bajo los signos, sólo sirve ya para explicar de modo delirante por qué las analogías son siempre frustradas. La erudición que leía como un texto único la naturaleza y los libros es devuelta a sus quimeras: depositados sobre las páginas amarillentas de los volúmenes, los signos del lenguaje no tienen ya más valor que la mínima ficción de lo que representan. La escritura y las cosas ya no se asemejan. Entre ellas, Don Quijote vaga a la aventura (Foucault 1968: 54-55). 
Andrés Rivera desde la fenomenología alegórica...

Castelli, en su parodia, al igual que Don Quijote, intenta llenar con los hechos los signos vacíos de otros textos, en su caso no de las novelas de caballería sino de los tratados de Rousseau o de Marat, pero inútilmente. Al igual que el texto de Cervantes, la novela es objeto de su propia narración convirtiéndose en texto autorreflexivo, como podemos observar a lo largo de todo el discurso del protagonista: «Escribo:...», «¿Yo escribí eso...?» (Rivera 2000: 15). Además, en la novela, Don Quijote aparece simbólicamente comparado con el Cid:

¿Leyó, doctor Castelli, El Cantar del Mío Cid?

....Leo un libro interminable: el Quijote.

¿Ese manual que enseña cómo perder el tiempo de la manera más estúpida posible?, pregunta Alzaga... Lea, doctor Castelli, El Cantar del Mío Cid: Los españoles son buenos vasallos cuando tienen un buen señor (Rivera 2000: 89; cursiva en el original).

El Cid no aparece en la biblioteca de Castelli. El protagonista no puede aceptar la lectura del Cid porque éste representa un tipo del protagonista heroico. Castelli, sin embargo, es un típico héroe melancólico, desprovisto de esa aura del héroe del cantar de gesta. Es un representante del fracaso de los ideales de la revolución argentina de 1810 y, sobre todo, el perdedor en las luchas utópicas.

\section{La lengua y la muerte}

Desde las primeras líneas de la novela, leemos un texto en el proceso de escritura y (re) lectura, las dos paralelamente realizadas por el protagonista justamente en el momento de su agonía a causa de un cáncer de lengua:

Escribo: un tumor me pudre la lengua. $Y$ el tumor que la pudre me asesina con la perversa lentitud de un verdugo de pesadilla.

¿Yo escribí eso, aquí, en Buenos Aires, mientras oía llegar la lluvia, el invierno, la noche? Escribí: mi lengua se pudre. ¿Yo escribí eso, hoy, un día de junio, mientras oía llegar la lluvia, el invierno, la noche?

Y ahora escribo: me llamaron - ¿importa cuándo?- el orador de la Revolución. Escribo: una risa larga y trastornada se enrosca en el vientre de quien fue llamado el orador de la Revolución. Escribo: mi boca no ríe. La podredumbre prohíbe, a mi boca, la risa (Rivera 2000: 15).

El narrador se cierra en el espejismo laberíntico de su texto escrito («Escribo:») y leído a la vez («¿Yo escribí eso...?») por él mismo, un texto que revela a través de ese espejismo textual la fragmentación del sujeto.

La lengua de Castelli que se pudre no puede hablar. Este hecho lo podemos leer como un proceso de alegorización de la physis. La lengua en la boca del protagonista representa la muerte que paulatinamente devora todo el cuerpo, mientras que el cuerpo escribe. Es significativo que la muerte, otro concepto fundamental, nos acompaña a lo largo del libro desde el inicio hasta el final. Benjamin afirma que en alegoría...

...se expresa [...] no sólo la condición de la existencia humana en general, sino también la historicidad biográfica de un individuo. Tal es el núcleo de la visión alegórica, de la exposición barroca y secular de la historia en cuanto historia de los padecimientos del mundo, el cual sólo es significativo en las fases de su decadencia. A mayor significación, mayor sujeción a la muerte, pues es la muerte la que excava más profundamente la abrupta línea de demarcación entre la physis y la significación (Benjamin 1990: 159; cursiva en el original). 
De acuerdo con Benjamin, la muerte se presenta como una fuente de todos los significados del lenguaje. La lengua del protagonista -un pedazo de carne moribunda- expresa la decadencia de la palabra y de la narración. Para Málek la novela tematiza la mutua y estrecha cooperación de la memoria y la muerte...

...ya que la autoridad de la narración tiene su fuente auténtica en la autoridad del moribundo, luego existe una profunda relación entre la decadencia de la narración y el desplazamiento de la muerte (Málek 2008: 127) ${ }^{3}$.

En la novela la muerte pierde su carácter aurático y, gracias a su teatralización, se convierte en una parodia cuyo protagonista es el ejemplo por excelencia de las paradojas de la Historia: un orador de la revolución que no puede hablar. El significado mítico de la muerte gracias a estos procedimientos queda destruido, convirtiéndose la muerte en un...

...objeto ejemplar de la alienación: en el sentido alegórico, la muerte ilustra el hecho de que puede ser liberada de su contexto (alienada de la naturaleza y del sujeto) y de que se le pueden atribuir otros significados arbitrarios (Málek 2008: 129) ${ }^{4}$.

Esa pérdida de carácter aurático la puede ejemplificar el siguiente fragmento de la novela:

Dicen que te llaman noche. Vení, noche, que aquí está Castelli. Vení, noche puta... Tachá las líneas que escribiste entre paréntesis: deberías saber, ya, que estos tiempos no propician la lírica (Rivera 2000: 48).

Esta alegorización de la muerte se convierte en un instrumento de la descripción de los procesos de alienación o de la pérdida de contextos, y en su propia parodia. El hombre no puede contar, ni puede morir:

Soñó que lo velaban. Su ataúd estaba vacío, y quienes lo velaban no sabían que el ataúd estaba vacío... Él abandonó a los que velaban un ataúd vacío, y caminó, por una pradera lisa y oscura e infinita, hacia el borde de la pradera lisa y oscura e infinita, hacia la esfera púrpura que se alzaba en el borde de la pradera lisa y oscura e infinita (Rivera 2000: 63).

El ataúd vacío se puede leer como metáfora del vacío del concepto de la muerte y su desplazamiento o separación de los moribundos, es decir, su alienación. La repetición ad infinitum de las palabras lleva al vaciamiento del significado.

El siguiente fragmento ilustra bien la relación entre la palabra y la muerte:

Castelli se pregunta dónde están sus palabras, qué quedó de ellas. La revolución -escribe Castelli, ahora, ahora que le falta tiempo para poner en orden sus papeles y respondersese hace con palabras. Con muerte. Y se pierde con ellas (Rivera 2000: 46).

La lengua (física), el instrumento indispensable de Castelli en el cargo de orador de la Revolución de Mayo, significa la muerte de la palabra impidiendo pronunciarla y causando la pérdida del sentido de la existencia del protagonista y el fin de su revolución silenciada.

\footnotetext{
3 Según el texto original: «nebot' autorita vyprávění má svůj autentický zdroj v autoritě umírajícího, pak existuje hluboká souvislost mezi úpadkem vyprávění a vytěsněním smrti» (la traducción es nuestra).

4 Según el texto original: «názorným objektem odcizení: ve svém alegorickém významu ozřejmuje, že může být uvolněna ze svého kontextu (odcizena př́rodě i subjektu) a mohou jí být připsány nové, libovolné významy» (la traducción es nuestra).
} 


\section{Castelli: un hombre contemporáneo}

De la fenomenología de la alegoría no agotamos todos los conceptos que esta figura es capaz de abarcar. Pero los que hemos destacado pueden apoyar suficientemente nuestra hipótesis y confirmar la profundidad y trascendencia del texto de Rivera, quien a través del tema histórico representa la existencia del sujeto en el momento de la caída de un orden (en este caso el colonial) cuyas consecuencias persisten hasta nuestros días. La lectura de la historia de la novela que elegimos (con el autor) es alegórica y, en función de la alegoría, convierte a su protagonista en actor o marioneta entendida esta como una cifra alegórica. De acuerdo con nuestra lectura, el texto de Rivera no tiene (sólo) la ambición de llenar lagunas en la historia oficial. En el paratexto de la novela que relaciona la revolución jacobina con la de los bolcheviques y con el peronismo (citas de Rousseau, Trotski, Lenin y Perón), hallamos y comprobamos el vínculo de la revolución con nuestra época, concretamente con la era postdictatorial argentina. La lectura minuciosa del mismo texto en el que el autor emplea una estrategia narrativa de la tematización de la escritura y del acto de la lectura nos llevó a la conclusión de que el objetivo principal del texto de Rivera era representar la crisis de los tiempos modernos en los que perviven los sueños eternos de la revolución.

\section{Bibliografía}

Avelar, Idelber (2000), Alegorías de la derrota: la ficción postdictatorial y el trabajo del duelo, Santiago de Chile: Editorial Cuarto Propio.

Benjamin, Walter (1990), El origen del drama barroco alemán, Madrid: Taurus.

BERG, Edgardo H. (2002), Poéticas en suspenso. Migraciones narrativas en Ricardo Piglia, Andrés Rivera y Juan José Saer, Buenos Aires: Editorial Biblos.

Foucault, Michel (1968), Las palabras y las cosas, Madrid: Siglo veintiuno editores.

MÁLEK, Petr (2008), Melancholie moderny, Praha: Dauphin.

Owens, Craig (1991), «El impulso alegórico. Hacia una teoría del postmodernismo», Atlántica. Revista de las Artes 1, 32-40.

Riva, Sabrina (2007), «La revolución es un sueño eterno de Andrés RiverA: una subjetiva genealogía del poder», Espéculo. Revista de estudios literarios 37 [en línea], <http:/ /www.zonamoebius.com/nudos-y-senales/la-revolucion-es-unsueno-eterno-de-andres-rivera-una-subjetiva-genealogia-del-poder $>$, fecha de consulta [10/07/2011].

Rivera, Andrés (2000), La revolución es un sueño eterno, Buenos Aires: Alfaguara.

Daniel Nemrava

Katedra romanistiky

Filozofická fakulta

Univerzita Palackého v Olomouci

Křížkovského 10

77180 Olomouc

República Checa

dnemrava@hotmail.com 